\title{
ANATOMICAL STUDY OF THE MESIOBUCCAL ROOT IN MAXILLARY FIRST MOLAR WITH DIFFERENT METHODS IN EGYPTIAN POPULATION
}

\author{
Soliman M. Kamha*
}

\begin{abstract}
Aim: to study the canal anatomy and its variations of mesiobuccal root of maxillary first molar using visual, $\mathrm{CT}, \mathrm{CBCT}$, and staining and clearing.

Materials and Methods: Three hundred extracted permanent maxillary first molar teeth were selected for this study. Mesio-buccal roots were resected $1 \mathrm{~mm}$ coronal to the trifurcation level. The orifices of the canals were located with a size $10 \mathrm{~K}$-type file which was passively advanced into the canals until the tip of the instrument penetrated the apical foramen for visual examination. The number of orifices and apical foramina in each root were recorded. All roots were embedded in a sheet of pink wax with vertical orientation and arranged in their numbers to facilitate three dimensional $\mathrm{CT}$ and $\mathrm{CBCT}$ scan and the data were stored on a magnetic optical disc. Both, CT and CBCT images were assessed by a calibrated dental radiology specialist blinded to the order of roots using Vitrea 2 V 3.8 imaging software. India ink was injected into the orifices of the root canals with a plastic disposable endodontic irrigating syringe with a $27-\mathrm{G}$ needle with suction tip which was placed at the root apex to draw the ink through the root canal system. All roots were decalcified with 5\% hydrochloric acid for three days, dehydrated in ascending concentrations of ethanol $(75 \%$, $85 \%, 96 \%$ and $100 \%$ ) for four hours each, and transparent specimens were obtained by immersing the dehydrated roots in methyl salicylate solution, in which the roots were stored until they were examined. The data regarding root canal morphology of each sample from all evaluation methods were tabulated and compared statistically.
\end{abstract}

Results: There were significant differences between the four methods used for studying the root canal anatomy of mesiobuccal root of first maxillary molars as regarding the number of canals, number of orifices, number of apical foramina, presence of lateral accessory canals and intercanal communications. Roots with three canals and three orifices and opened apically with two foramina showed no significant differences between the four methods. Also, with Kappa test, there was good and fair agreement between CBCT \& CT and CBCT \& staining and clearing respectively.

Conclusion: the most detailed information can be obtained in-vitro by staining and clearing and high resolution $\mathrm{CT}$ and $\mathrm{CBCT}$ methods which are commonly used as a diagnostic aid in clinical endodontics.

KEYWORDS: CT, CBCT, Staining and clearing, canal anatomy

\footnotetext{
* Lecturer of Endodontics, Faculty of Dentistry, Pharos University.
} 


\section{INTRODUCTION}

The first molar is the first tooth in need of endodontic treatment when it is exposed by decay because it is the earliest permanent tooth appeared in the oral cavity ${ }^{[1,2]}$.

The maxillary first molars have the most complex morphology. It is one of the most misunderstood teeth. The mesiobuccal roots of maxillary molars show greater variation in their root canal systems than distobuccal and palatine roots ${ }^{[3]}$. These systems communicate frequently along their lengths, and terminate separately in two or more portals of exit greater than 58 percent of the time. Therefore, it is assumed that all maxillary first molars have four canals until proven otherwise ${ }^{[4]}$.

The majorities of the mesiobuccal roots have two canals for their broad buccolingual dimensions and associated concavities on their mesial and distal surfaces with high incidence up to $95 \%$ of cases ${ }^{[5-8]}$. There is a wide range of variation in the number of canals and incidence of fusion ${ }^{[9]}$.

The exploration of the entire root canal system, thorough chemo-mechanical cleansing followed by obturation using inert filling materials and a sealant are the key of endodontic treatment success ${ }^{[10,11]}$. Any existing root canals that remain undetected by the dentist during the entire course of endodontic treatment are a major threat to the failure of treatment. So, it is essential to know the detailed knowledge of root canals morphology ${ }^{[12]}$.

Isthmuses and accessory canals are anatomical structures, when they are present in the root canal system, cooperate to the endodontic treatment failures, as they can act as reservoirs of bacteria and necrotic pulp tissues ${ }^{[13]}$. According to Weller et al. (1995) ${ }^{[14]}$, an isthmus is defined as a narrow ribbonshaped communication between two root canals containing pulp tissue.

The highest failure rates occur in maxillary first molars due to anatomy complexities, number of canals, difficulty to find and access the canals orifices, especially the second mesiobuccal (MB2) ${ }^{[15,16]}$. Thus, the most predictable treatment outcome is achieved when the clinician has an accurate knowledge of root canal morphology to guide both surgical and non-surgical endodontic therapy.

It is essential to provide insight into root canal anatomy complexities through the knowledge from laboratory studies. Many investigators have used different methods to ascertain the number of canals, ramifications of the main root canal, localization and number of foramina and presence of apical deltas ${ }^{[1]}$.

An ideal technique for studying the root canal anatomy would be accurate, simple, nondestructive, feasible and reproducible in an in vivo scenario ${ }^{[17,18]}$.

Previous studies used many methods for studying the root canal morphology of the mesiobuccal root of upper molars including canal staining and tooth clearing, conventional radiographs, digital radiographic techniques, radiographic assessment enhanced by contrast media and recently computed tomography (CT) technique ${ }^{[17]}$. One of the most important studies was performed by Walter Hess (1925) ${ }^{[19]}$, who injected the root canals with a specific ink and visualized the huge amount of variables and complexities of root canal systems.

Radiographic techniques have been used to obtain a two-dimensional image ${ }^{[20-22]}$.

Three-dimensional methods for the morphological study of teeth are replacing the more limited twodimensional techniques. It allows 3D reconstruction of root canal systems with the ability to distinguish details in each canal ${ }^{[17]}$.

More recently, with Improvements in digital imaging systems, CBCT is introduced as a nondestructive method with capability of 3D imaging for in vivo evaluation of root canal anatomy, which has considerably lower radiation dose than conventional CT ${ }^{[23,24]}$. 
Computed tomography (CT) was shown to be accurate for experimental endodontology. Their images can be formed from planar slices through objects which can be physical sections, optical sections or CT reconstructions ${ }^{[25]}$. With technological advances, using the operating microscope in clinical practice may facilitate the location and treatment of additional canals ${ }^{[26]}$.

CBCT is a non-invasive technique which improves the detection of additional roots and root canals, including the second mesiobuccal canal of the mesiobuccal root of maxillary molars. It allows three-dimensional visualization of images, assisting in the identification of anatomical features and variations in the root canal system [15,17,26,27,28]. This technology produces excellent quality with a significantly lower effective radiation dose compared with conventional CT ${ }^{[29,30]}$. Besides, its benefits are lower exposure time, higher resolution and accuracy ${ }^{[20,21,31]}$.

Many studies were published on the internal anatomy of posterior teeth with very littleinformation exist regarding the accuracy of clearing, $\mathrm{CBCT}$ and micro-CT methods to identify the morphology of the root canal anatomy ${ }^{[32-34]}$.

The aim of the current study was to compare the efficacy of different methods, named visual, CT, CBCT and staining and clearing in studying the root canal anatomy in mesiobuccal root of maxillary first molar in Egyptian population.

\section{MATERIALS AND METHODS}

\section{Selection of samples}

Three hundred extracted permanent maxillary first molar teeth with fully formed apices that were not endodontically treated were collected from Endodontic Department teeth bank of Pharos University in Alexandria.

\section{Preparation of samples}

The sample teeth were washed under tap water for 30 minutes. Mesio-buccal roots were resected 1 $\mathrm{mm}$ coronal to the trifurcation level and immersed in $2.5 \%$ sodium hypochlorite for 30 minutes to remove adherent soft tissue. The roots were physically scraped using a scalpel blade and an ultrasonic scaler for cleaning from calculus and stains. The roots were immersed in $2.5 \%$ sodium hypochlorite for 24 hours to dissolve the organic debris and pulp tissue remnants from the root canal systems ${ }^{[35-37]}$. All roots were rinsed under running tap water for two hours and then, stored in normal saline until they used.

\section{Visual evaluation}

The orifices of the canals were located with a size 10 K-type file (Dentsply / Sirona, Ballaigues, Switzerland), which was passively advanced into the canals until the tip of the instrument penetrated the apical foramen. The number of orifices and apical foramina in each root were recorded in a schedule as regard the root number. For standardizing the data observed, this procedure carried out by a single operator.

\section{CT scanning}

All roots were embedded in a sheet of pink wax with vertical orientation and arranged in their numbers to facilitate three dimensional CT scan in its platform by Multislice CT device (Toshiba, Aquillion one 640 slices, Japan) and the data were stored on a magnetic optical disc.

\section{CBCT scanning}

The same roots in their wax platform with the same arrangement were submitted to CBCT scan (Veraviewepocs 3D R100, MORITA, Kyoto, Japan) and the data were stored on a magnetic optical disc.

Both, CT and CBCT images were assessed by a calibrated dental radiology specialist blinded 
to the order of roots using Vitrea $2 \mathrm{~V} 3.8$ imaging software (Vitrea 2, Vital Imaging Inc.) from root cross-sections, axial and coronal images to view the internal root canal anatomy from various angles. The area of interest were magnified to make observations regarding root morphology (number of canal orifices, number of canal exits, number of canals, presence of second mesio-buccal canal, presence of apical deltas, complex apical ramifications, number and location of inter-canal communications) and tabulated.

\section{Staining of roots}

All roots got out the wax platform with their numbers were washed under running tap-water for two hours and placed on tissue paper and allowed to dry overnight.

India ink was injected into the orifices of the root canals with a plastic disposable endodontic irrigating syringe with a $27-\mathrm{G}$ needle with suction tip was placed at the root apex to draw the ink through the root canal system and to be sure about the flow of the ink to all canals, communications, deltas, and ramifications. The appearance of ink at the apical foramen indicated the end of the process. The teeth were dried overnight again for 12 hours.

\section{Clearing of roots}

All roots were decalcified with 5\% hydrochloric acid for three days, the acid solution being changed daily. Then, roots were again washed under running tap-water overnight and air-dried. The specimens were then dehydrated in ascending concentrations of ethanol $(75 \%, 85 \%, 96 \%$ and $100 \%)$ for four hours each, and transparent specimens were obtained by immersing the dehydrated roots in methyl salicylate solution, in which the roots were stored until they were examined ${ }^{[38-40]}$. The transparent specimens were then examined by the naked eye as well as under stereomicroscope (Olympus SZ 1145 TR, Tokyo, Japan, and Mag.110 X) and digital micrographic images with their numbers were captured and saved for evaluation.
The data regarding root canal morphology of each sample from all evaluation methods were tabulated based on the number of root canals, number of root canal orifices, number of apical foramina, apical deltas, apical ramifications, presence of lateral canals, and inter-canal communications and compared statistically.

\section{Statistical analysis of the data}

Data were fed to the computer and analyzed using IBM SPSS software package version 20.0. Comparisons between groups for categorical variables were assessed using Chi-square test (Monte Carlo). Kappa $(\varkappa$ ) for agreement was used. Significance of the obtained results was judged at the $5 \%$ level.

\section{RESULTS}

\section{Visual observations}

Out of three hundred mesio-buccal roots of maxillary first molar,

72 roots $(24 \%)$ showed one canal with one orifice and open apically in one apical foramen. 228 roots (76.00\%) showed two canals with tow orifices, $61(20.33 \%)$ of them open apically in Two apical foramina and 167 roots (55.67\%) joined together and opened apically in one apical foramen. (Figure 1) (Table 1)

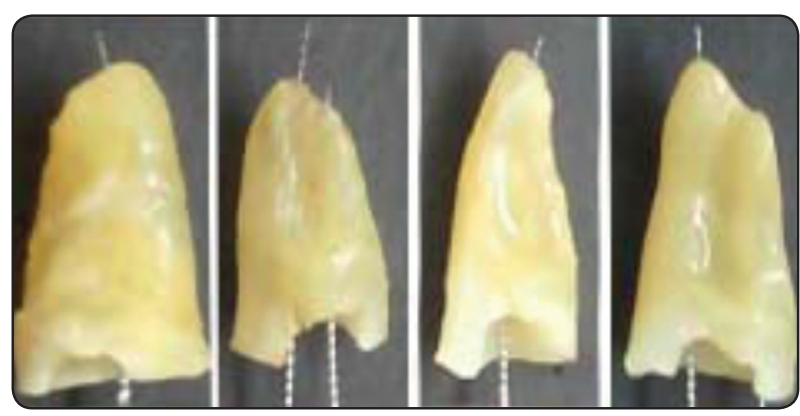

Fig. (1) Visual observations of MB root of maxillary first molar with files 


\section{CT observations}

Out of three hundred mesio-buccal roots of maxillary first molar, 117 roots $(39.00 \%)$ showed one canal with one orifice, $73(24.33 \%)$ of them open apically in one apical foramen, 32 roots $(10.67 \%)$ open apically in apical deltas, 3 roots $(1 \%)$ open apically in apical ramifications, and 9 roots $(3 \%)$ open apically in one foramen with lateral accessory canals. 183 roots $(61.00 \%)$ showed two canals with two orifices, $21(7 \%)$ of them open apically in two apical foramina, 99 roots (33\%), the two canals joined together and opened apically in one apical foramen, 28 roots $(9.33 \%)$, one of these two canals open in one apical foramen and the other canal open apically in apical deltas, 4 roots $(1.33 \%)$ open apically in apical ramifications, 12 roots (4\%) the two canals joined in one canal and open apically in one apical foramen with lateral accessory canals, and 19 roots $(6.33 \%)$ the two canals joined in the middle third and opened apically in two foramina.

(Figure 2) (Table 1)
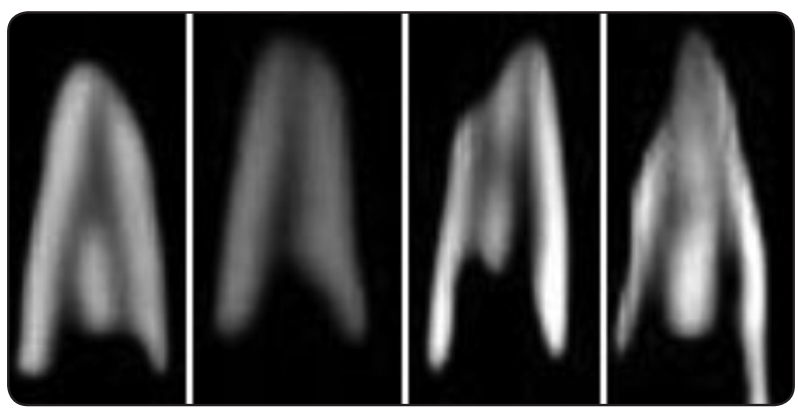

Fig. (2) CT observations of MB root canal anatomy of maxillary first molar

\section{CBCT observations}

Out of three hundred mesio-buccal roots of maxillary first molar, 97 roots $(32.33 \%)$ showed one canal with one orifice, $44(14.67 \%)$ of them open apically with one apical foramen, 38 (12.67\%) roots open apically with apical deltas, $6(2.00 \%)$ roots open apically with apical ramifications, and $9(3 \%)$ roots open apically with one foramen and lateral accessory canals. $200(66.67 \%)$ roots showed two canals with two orifices, $22(7.33 \%)$ of them open apically with two apical foramina, 60 roots $(20.00 \%)$, the two canals joint to one canal and open apically with one apical foramen, 47 roots $(15.67 \%)$, one of the two canals open apically with one apical foramen and the other canal open apically with apical deltas, 6 roots $(2.00 \%)$ opened apically with apical ramifications, 14 roots $(4.67 \%)$ open apically with two apical foramina with lateral accessory canals, 34 roots $(11.33 \%)$ open apically with two apical foramina and communications between the two canals in the middle third,10 roots (3.33\%) open apically with two apical foramina after joining in the middle third, and 7 roots $(2.33 \%)$ showed two canals joint to one canal, bifurcated to two and rejoined again to open apically with one apical foramen. 3 roots $(1 \%)$ showed three canals with three orifices and open apically in two foramina. (Figure 3) (Table 1)

\section{Staining and clearing observations}

Out of three hundred mesio-buccal roots of maxillary first molar, 64 roots showed one canal with one orifice $26(8.67 \%)$ of them open apically with one apical foramen, 22 roots $(7.33 \%)$ open
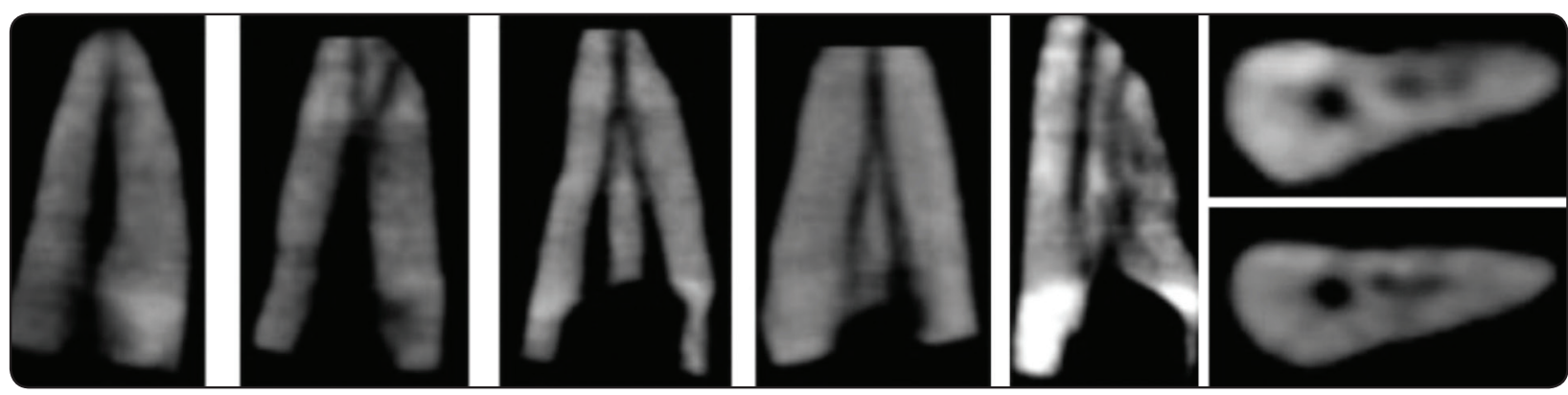

Fig. (3) CBCT observations of MB root canal anatomy of maxillary first molar 
apically with apical deltas, 6 roots $(2.00 \%)$ open apically with apical ramifications, and 10 roots $(3.33 \%)$ open apically with one apical foramen and lateral accessory canals. 236 roots $(78.67 \%)$ showed two canals with two orifices, 22 roots $(7.33 \%)$ of them the two canals open apically with two separate foramina, 119 roots (39.67), the two canals joined together and opened apically with one apical foramen, 48 roots $(16.00 \%)$ one canal open apically in one apical foramen and the other canal open apically with apical deltas, 9 roots $(3.00 \%)$ open apically with apical ramifications, 15 roots $(5.00 \%)$ open apically with two apical foramina with lateral accessory canals, 7 roots $(2.33 \%)$ open apically with two apical foramina and communications between the two canals in the middle third, and 16 roots $(5.33 \%)$ open apically with two apical foramina after joining in the middle third. (Figure 4) (Table 1)

Comparison between visual, CT, CBCT, and staining and clearing procedures for detecting the canals configurations of the mesio-buccal root of maxillary first molar, it was found that, out of 300, $72(24.0 \%), 117$ (39.0\%), 97 (32.3\%), and 64 $(21.3 \%)$ roots respectively showed one canal with one orifice with mean value of these percentages $29.17 \%$ and significant difference between them. Also, it was found that, out of 300, $228(76.0 \%)$, $183(61.0 \%), 200$ (66.7\%), and 236 (78.7) roots respectively showed two canals with two orifices with mean value of these percentages $70.59 \%$ and significant difference between them. (Table 1) (Figure 1)

Comparison between visual, CT, CBCT, and staining and clearing procedures either in one canal with one orifice or two canals with two orifices with their variation in apical opening (with one apical foramen, two apical foramina, apical deltas, apical ramifications, lateral accessory canals or communications between the canals) revealed significant statistically difference between them. (Table 1) (Figure 1)

Comparison between visual, CT, CBCT, and staining and clearing procedures, $\mathrm{CBCT}$ was the only procedure showing three canals with three orifices and opened apically in two foramina in 3 roots $(1.00 \%)$ revealed no significant statistically difference. (Table 1) (Figure 1)

Evaluation of inter-method agreement between $\mathrm{CT}$ and $\mathrm{CBCT}$ in relation to canal anatomy in the mesio-buccal root of maxillary first molar (one orifice with one foramen, one orifice with two foramina, two orifices with two foramina, and two orifices with one foramen) showed a kappa coefficient of 0.622 which is good level of agreement revealing statistically significant difference $(\mathrm{P}<0.001)$. (Table 2)

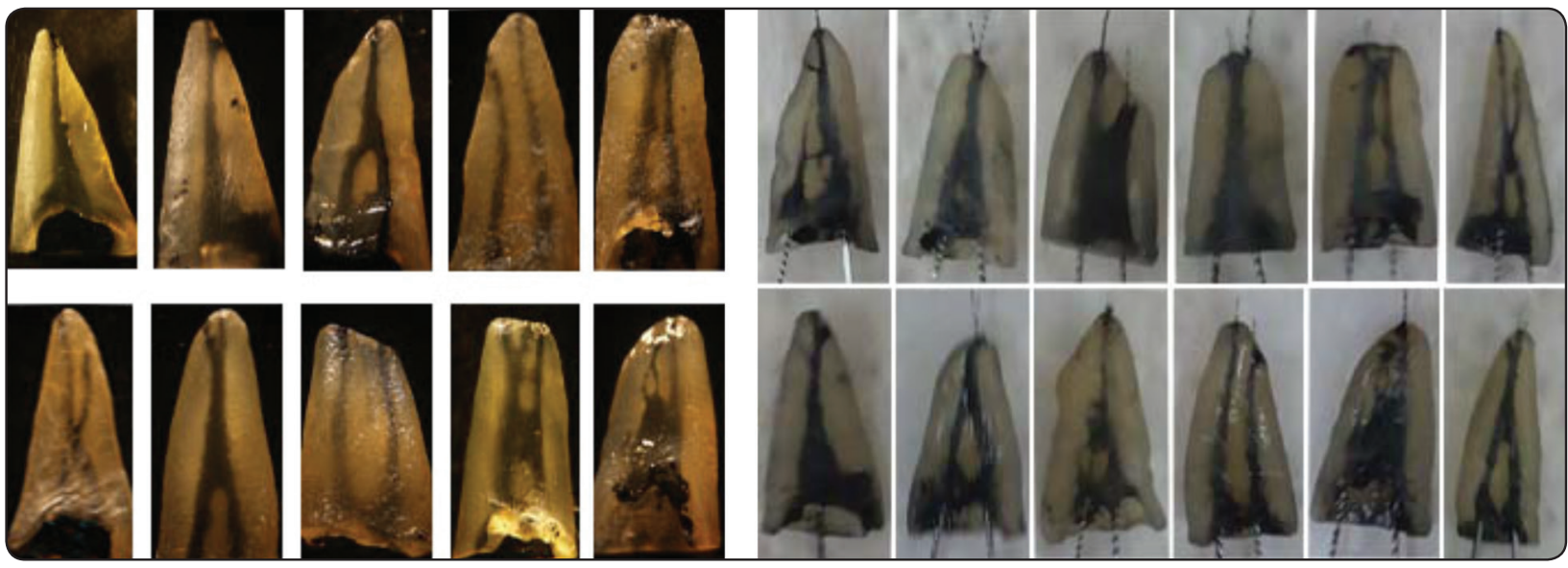

Fig. (4) Staining and clearing observations of MB root canal anatomy of maxillary first molar 


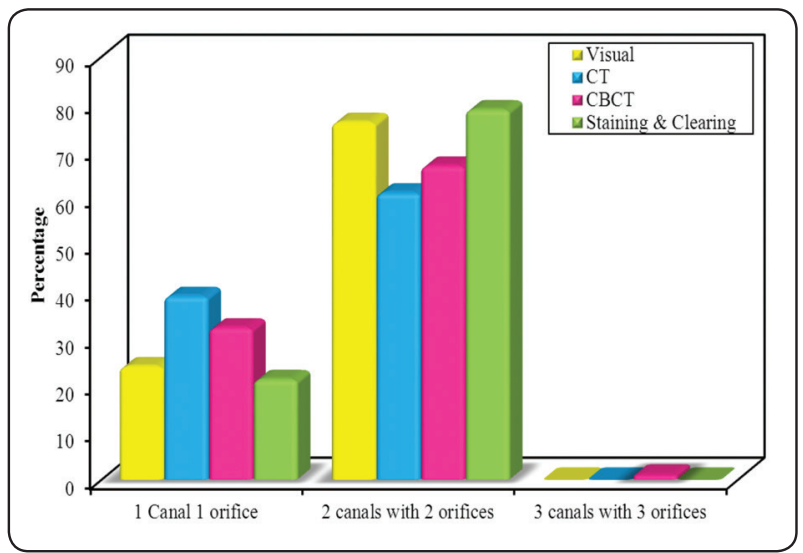

Fig. (5): Comparison between Visual, CT, CBCT, Staining and clearing percentage of observations in different root canal configurations in mesio-buccal root of maxillary first molar.

Table (1) Comparison between Visual, CT, CBCT, Staining and clearing percentages of observations in different root canal configurations in mesio-buccal root of maxillary first molar.

\begin{tabular}{|c|c|c|c|c|c|c|c|}
\hline & Open apically with & $\begin{array}{c}\text { Visual } \\
(n=300)\end{array}$ & $\begin{array}{c}\text { CT } \\
(n=300)\end{array}$ & $\begin{array}{c}\text { CBCT } \\
(n=300)\end{array}$ & $\begin{array}{c}\text { Staining \& } \\
\text { Clearing } \\
(n=300)\end{array}$ & $c^{2}$ & $\mathbf{p}$ \\
\hline \multirow{5}{*}{$\begin{array}{c}1 \text { canal } 1 \\
\text { orifice }\end{array}$} & & $72(24.0 \%)$ & $117(39.0 \%)$ & $97(32.3 \%)$ & $64(21.3 \%)$ & $28.284^{*}$ & $<0.001^{*}$ \\
\hline & 1 Foramen & $72(24 \%)$ & $73(24.3 \%)$ & $44(14.7 \%)$ & $26(8.7 \%)$ & $36.683^{*}$ & $0.001^{*}$ \\
\hline & Ap. Delta & $0(0.0 \%)$ & $32(10.7 \%)$ & $38(12.7)$ & $22(7.3)$ & $39.366^{*}$ & $<0.001^{*}$ \\
\hline & Ap. Ramification. & $0(0.0 \%)$ & $3(1.0 \%)$ & $6(2.0 \%)$ & $6(2.0 \%)$ & $7.682^{*}$ & ${ }^{\mathrm{MC}} \mathrm{p}<0.048^{*}$ \\
\hline & Lat accessory & $0(0.0 \%)$ & $9(3.0 \%)$ & $9(3.0 \%)$ & $10(3.3 \%)$ & $9.654^{*}$ & $0.022^{*}$ \\
\hline \multirow{9}{*}{$\begin{array}{c}2 \text { canals } \\
\text { with } \\
2 \text { orifices }\end{array}$} & & $228(76.0 \%)$ & $183(61.0 \%)$ & $200(66.7 \%)$ & $236(78.7)$ & $29.166^{*}$ & $<0.001^{*}$ \\
\hline & 2 Foramina & $61(20.3 \%)$ & $21(7.0 \%)$ & $22(7.3 \%)$ & $22(7.3 \%)$ & $41.181^{*}$ & $<0.001^{*}$ \\
\hline & 1 Foramen & $167(55.7 \%)$ & $99(33.0 \%)$ & $60(20.0 \%)$ & $119(39.7 \%)$ & $84.931^{*}$ & $<0.001^{*}$ \\
\hline & Ap. Delta & $0(0.0 \%)$ & $28(9.3 \%)$ & $47(15.6 \%)$ & $48(16.0 \%)$ & $54.886^{*}$ & $<0.001^{*}$ \\
\hline & Ap. Ramification & $0(0.0 \%)$ & $4(1.3 \%)$ & $6(2.0 \%)$ & $9(3.0 \%)$ & $10.460^{*}$ & ${ }^{\mathrm{MC}} \mathrm{p}<0.009^{*}$ \\
\hline & Lat Accessory & $0(0.0 \%)$ & $12(4.0 \%)$ & $14(4.6 \%)$ & $15(5.0 \%)$ & $14.622^{*}$ & $0.002^{*}$ \\
\hline & $\begin{array}{c}\text { With lateral } \\
\text { communications }\end{array}$ & $0(0.0 \%)$ & $0(0.0 \%)$ & $34(11.3 \%)$ & $7(2.3 \%)$ & $79.269^{*}$ & $<0.001^{*}$ \\
\hline & $\begin{array}{c}\text { Joined in } \mathrm{m} .1 / 3 \\
\text { open in } 2 \text { Foramina }\end{array}$ & $0(0.0 \%)$ & $19(6.3 \%)$ & $10(3.3 \%)$ & $16(5.3 \%)$ & $19.463^{*}$ & $<0.001^{*}$ \\
\hline & $\begin{array}{c}\text { Joined, bifurcat, } \\
\text { rejoined and } \\
\text { open in } 1 \text { Foramen }\end{array}$ & $0(0.0 \%)$ & $0(0.0 \%)$ & $7(2.3 \%)$ & $0(0.0 \%)$ & $13.725^{*}$ & ${ }^{\mathrm{MC}} \mathrm{p}<0.001^{*}$ \\
\hline $\begin{array}{c}3 \text { canals } \\
\text { with } \\
3 \text { orifices }\end{array}$ & 2 Foramen & $0(0.0 \%)$ & $0(0.0 \%)$ & $3(1.0 \%)$ & $0(0.0 \%)$ & 5.076 & $\begin{array}{l}{ }^{\mathrm{MC}} \mathrm{p}= \\
0.064\end{array}$ \\
\hline
\end{tabular}

$c^{2}, p: c^{2}$ and $p$ values for Chi square test for comparing between the different groups

${ }^{M C}$ : $p$ value for Monte Carlo for Chi square test for comparing between the different groups

*: Statistically significant at $p \leq 0.05$ 
TABLE (2): Agreement between CT \& CBCT

\begin{tabular}{|c|c|c|c|c|c|c|c|c|c|c|}
\hline & \multicolumn{8}{|c|}{ CT } & \multirow{3}{*}{$x$} & \multirow{3}{*}{$\mathbf{p}$} \\
\hline & \multicolumn{2}{|c|}{$\begin{array}{c}1 \text { orifice } \\
1 \text { foramen }\end{array}$} & \multicolumn{2}{|c|}{$\begin{array}{c}1 \text { orifice } \\
2 \text { foramina }\end{array}$} & \multicolumn{2}{|c|}{$\begin{array}{c}2 \text { orifices } 2 \\
\text { foramina }\end{array}$} & \multicolumn{2}{|c|}{$\begin{array}{c}2 \text { orifices } 1 \\
\text { foramen }\end{array}$} & & \\
\hline & No. & $\%$ & No. & $\%$ & No. & $\%$ & No. & $\%$ & & \\
\hline CBCT & & & & & & & & & & \\
\hline 1 orifice 1 foramen & 92 & 30.67 & 7 & 2.33 & 5 & 1.67 & 0 & 0.0 & & \\
\hline 1 orifice 2 foramina & 14 & 6.67 & 0 & 0.0 & 0 & 0.0 & 0 & 0.0 & $0.622^{*}$ & \\
\hline 2 orifices 2 foramina & 7 & 2.33 & 0 & 0.0 & 36 & 12.0 & 33 & 11.0 & agreement & \\
\hline 2 orifices 1 foramen & 5 & 1.67 & 0 & 0.0 & 5 & 1.67 & 96 & 32.0 & & \\
\hline
\end{tabular}

«: kappa test

*: Statistically significant at $p \leq 0.05$

\begin{tabular}{|c|c|}
\hline Value of K & Strength of agreement \\
\hline$<0.20$ & Poor \\
\hline $0.21-0.40$ & Fair \\
\hline $0.41-0.60$ & Moderate \\
\hline $0.61-0.80$ & Good \\
\hline $0.81-1.00$ & Very good \\
\hline
\end{tabular}

Evaluation of inter-method agreement between staining and clearing and CBCT in relation to canal anatomy in the mesio-buccal root of maxillary first molar (one orifice with one foramen, one orifice with two foramina, two orifices with two foramina, and two orifices with one foramen) showed a kappa coefficient of 0.360 which is fair level of agreement revealing statistically significant difference $(\mathrm{P}<0.001)$. (Table 3)

TABLE (3): Agreement between staining and clearing \& CBCT

\begin{tabular}{|c|c|c|c|c|c|c|c|c|c|c|}
\hline & & & & taini & and $\mathrm{C}$ & ing & & & \multirow{3}{*}{$x$} & \multirow{3}{*}{$\mathbf{p}$} \\
\hline & \multicolumn{2}{|c|}{$\begin{array}{l}1 \text { orifice } \\
1 \text { foramen }\end{array}$} & \multicolumn{2}{|c|}{$\begin{array}{c}1 \text { orifice } \\
2 \text { foramina }\end{array}$} & \multicolumn{2}{|c|}{$\begin{array}{c}2 \text { orifices } \\
2 \text { foramina }\end{array}$} & \multicolumn{2}{|c|}{$\begin{array}{l}2 \text { orifices } \\
1 \text { foramen }\end{array}$} & & \\
\hline & No. & $\%$ & No. & $\%$ & No. & $\%$ & No. & $\%$ & & \\
\hline \multicolumn{11}{|l|}{ CBCT } \\
\hline 1 orifice 1 foramen & 33 & 11.0 & 30 & 10.0 & 5 & 1.67 & 22 & 7.33 & \multirow{4}{*}{$\begin{array}{l}\quad 0.360^{*} \\
\text { Fair agreement }\end{array}$} & \multirow{4}{*}{$<0.001^{*}$} \\
\hline 1 orifice 2 foramina & 8 & 2.67 & 0 & 0.0 & 10 & 3.33 & 0 & 0.0 & & \\
\hline 2 orifices 2 foramina & 0 & 0.0 & 0 & 0.0 & 61 & 20.33 & 23 & 7.67 & & \\
\hline 2 orifices 1 foramen & 0 & 0.0 & 0 & 0.0 & 38 & 12.67 & 70 & 23.33 & & \\
\hline
\end{tabular}

ж: kappa test

*: Statistically significant at $p \leq 0.05$ 


\section{DISCUSSION}

The clinical cause of failures in root canal treatment of mesiobuccal roots of maxillary molars might occur because of their anatomical complexities, multiple canals and occasionally difficulty of finding canals, especially the second mesiobuccal canal. Therefore, it is important to investigate root canal morphology of maxillary first molar ${ }^{[15]}$. So, it is important to know enough knowledge about the root canal anatomy and possible variations of the maxillary molars to achieve successful endodontic therapy.

There are many methods for studying the root and canal morphology of teeth including staining and tooth clearing, dental model preparation with clear resin, decalcification, dissecting and sectioning, direct examination or magnification and microscope surgery, loops with fiber optic, conventional radiography and recently $3 \mathrm{D}$ imaging with $\mathrm{CT}$ and $\mathrm{CBCT}{ }^{[41]}$.

This study examined the root canal morphology with its variations of mesiobuccal root of maxillary first molars in Egyptian population. Visual, CT, $\mathrm{CBCT}$, and staining and clearing methods were used.

It has been reported that the most detailed information can be obtained ex vivo by staining and clearing which resulted in very clear specimens, allowing good visualization and photography of the canal anatomy ${ }^{[2,43]}$.

Nondestructive high resolution Computed tomography (CT) ${ }^{[44]}$ and cone beam computed tomography (CBCT) ${ }^{[45]}$ scanning techniques are commonly used as a diagnostic aid in clinical endodontics. They allow for the cross-sectional analysis of the specimens, allow the development of a more accurate and detailed 3D models of the root canal space and better imaging of inter-canal connections, accessory canals and multiple apical foramina which is not feasible with the clearing technique.
In the current study, the number of root canals in the mesio-buccal root of maxillary first molars in Egyptian population shows wide range of variations which agree with the report of Sempira and Hartwell (2000) ${ }^{[46]}$

In our study the mesiobuccal root contained single canal in $24 \%$ by visual, $39 \%$ by CT, $32.3 \%$ by CBCT, and $21.3 \%$ by staining and clearing with mean $29.2 \%$ and two canals in $76 \%$ by visual, $61 \%$ by $\mathrm{CT}, 66.7 \%$ by $\mathrm{CBCT}$, and $78.7 \%$ by staining and clearing with mean $70.6 \%$ of cases. This results are in agreement with the results of Imura et al (1998) [47], who stated that, the graduate students found two mesiobuccal root canals in 52\% of extracted maxillary first molar teeth, while the incidence of two mesiobuccal roots rose to $81 \%$ after the same root was made transparent. Also, our result was in agreement with Marroquin et al (2004) ${ }^{[48]}$ who reported two foramina in approximately $70 \%$ of maxillary first molar mesiobuccal roots.

The wide variation in the frequency of two mesiobuccal roots canals (40-95\%) may be related to the methods used for determining additional canals. For instance, two mesiobuccal root canals were identified significantly less frequently in clinical studies than in vitro ${ }^{[49]}$.

Results of the present study showed that $29.2 \%$ of the roots had a single canal and $70.6 \%$ had two or more canals which were in disagreement with Habib (2014) ${ }^{[50]}$ who found that, of the stained and cleared 95 maxillary first molars studied, 57 (60\%) had a single canal in the mesiobuccal root, and 38 (40\%) had two canals. Also, the results were in contrast to Cleghorn et al (2006) ${ }^{[1]}$ and Grande et al (2008) ${ }^{[51]}$ who reported that, a single canal in the mesiobuccal root of maxillary first molar was found in approximately two-thirds of roots, and two canals were present in one third of roots. But it was near to the report of Tam and Yu (2002) ${ }^{[52]}$ who found that, there was a single canal in $36 \%$ of the roots and two canals in $64 \%$ of the roots in a cross-sectional study of the mesiobuccal root. 
Also, the results of the current study were similar to the results of Alrahabi and Zafar (2015) ${ }^{[45]}$ who concluded that, the occurrence of second (mesiopalatal) canal in the maxillary first molar in mesiobuccal root was very much likely more than $70 \%$.

Intercanal communications may be poorly accessible to chemomechanical instrumentation and may act as bacterial reservoirs, resulting in persistent periapical pathosis. The present study found intercanal communications in $11.3 \%$ of the roots examined which were in disagreement with Vertucci (1984) ${ }^{[10]}$ who reported a $52 \%$ incidence of transverse anastomosis, but, it is in agreement with other studies showing that, the inter-canal communications were located mostly in the middle third of the root ${ }^{[52,53]}$.

The present study showed a kappa coefficient of 0.622 which is good level of agreement between $\mathrm{CT}$ and CBCT revealing statistically significant difference $(\mathrm{P}<0.001)$ in detection of $\mathrm{MB} 2$ in mesiobuccal root of the first maxillary molars of Egyptian population. It was similar to the agreement of results between Zhang et al. (2011) ${ }^{[54]}$ who reported that, MB2 were found in 52\% of samples in Chinese population using CBCT and Rathi et al. (2010) ${ }^{[55]}$ who evaluated the frequency of MB2 by $\mathrm{CT}$ and reported its percentage as $57 \%$.

In the present study, the evaluation of intermethod agreement between staining and clearing and CBCT methods for determining the mesiobuccal root configurations in Egyptian population showed a kappa coefficient of 0.360 which is fair level of agreement revealing statistically significant difference $(\mathrm{P}<0.001)$. This result was in agreement with Zheng et al. (2010) ${ }^{[56]}$ who found $50 \%$ of cases have MB2 in Chinese population using CBCT while Wasti et al. (2001) ${ }^{[38]}$ used tooth staining and clearing technique and found the second mesiobuccal frequency in maxillary first molar as $52 \%$.

\section{CONCLUSION}

Although staining and clearing was shown to be superior than other methods used in the present study, still it is impossible to be relied upon since it cannot be done clinically. Results of our study recommend using of CBCT and CT to study complicated cases, since they can be performed clinically.

\section{REFERENCES}

1- Cleghorn BM, Christie WH, Dong CCS. Root and root canal morphology of the human permanent maxillary first molar: A literature review. J Endod. 2006; 32(9):813-821.

2- Rizvi A, Zafar MS, Farid WM, Gazal G. Assessment of antimicrobial efficacy of MTAD, sodium hypochlorite, EDTA and chlorhexidine for endodontic applications: An in vitro study. Middle-East J Sci Res. 2014; 21(2):353-357.

3- Silva EJNL, Nejaim Y, Silva AIV, Haiter-Neto F, Zaia AA, Cohenca N. Evaluation of root canal configuration of maxillary molars in a Brazilian population using cone-beam computed tomographic imaging: an in vivo study. J Endod 2014; 40:173-176

4- Ruddle CJ: The Mesial-Buccal Root of the Maxillary First Molar: Treatment Considerations. The Endodontic Report, Fall / Winter, 1986.

5- Pécora JD, Woelfel JB, Sousa Neto MD, Issa EP. Morphologic study of the maxillary molars. Part II: Internal anatomy. Braz Dent J 1992; 3:53-7.

6- Hartwell G, Appelstein CM, Lyons WW, Guzek ME. The incidence of four canals in maxillary first molars: A clinical determination. J Am Dent Assoc 2007; 138:1344-6.

7- Hartwell G, Bellizzi R. Clinical investigation of in vivo endodontically treated mandibular and maxillary molars. J Endod 1982; 8:555-7.

8- Kulild JC, Peters DD. Incidence and configuration of canal systems in the mesiobuccal root of maxillary first and second molars. J. Endod 1990; 16:311-7.

9- Walton R, Torabinejad M. Principles and practice of endodontics, 2nd ed. Philadelphia: W.B. Saunders Co., 1996.

10- Vertucci FJ. Root canal anatomy of the human permanent teeth. Oral Surg Oral Med Oral Pathol. 1984; 58(5):589-599.

11- Omer OE, Al Shalabi RM, Jennings M, Glennon J, Claffey NM. A comparison between clearing and radiographic 
techniques in the study of root-canal anatomy of maxillary first and second molars. Int Endod J 2004; 37(5): 291-296.

12- Weine FS, Healey HJ, Gerstein H, Evanson L. Canal configuration in the mesiobuccal root of the maxillary first molar and its endodontic significance. Oral Surg Oral Med Oral Pathol. 1969; 28(3):419-425.

13- Jung IY, Seo MA, Fouad AF, Spångberg LSW, Lee S-J, Kim H-J. Apical anatomy in mesial and mesiobuccal roots of permanent first molars. J. Endod 2005; 31:364-368.

14- Weller NR, Niemczyk SP, Kim S. Incidence and position of the canal isthmus. Part 1. Mesiobuccal root of the maxillary first molar. J. Endod 1995; 21:380-383.

15- Blattner TC, George N, Lee CC, Kumar V, Yelton CD. Efficacy of cone-beam computed tomography as a modality to accurately identify the presence of second mesiobuccal canals in maxillary first and second molars: a pilot study. J. Endod. 2010; 36(5):867-70.

16- Smadi L, Khraisat A. Detection of a second mesiobuccal canal in the mesiobuccal roots of maxillary first molar teeth. Oral Surgery Oral Med Oral Pathol Oral Radiol Endod. 2007; 103(3):77-81.

17- Neelakantan P, Subbarao C, Subbarao CV. Comparative evaluation of modified canal staining and clearing technique, cone-beam computed tomography, peripheral quantitative computed tomography, spiral computed tomography, and plain and contrast medium-enhanced digital radiography in studying root canal morphology. J. Endod. 2010b; 36, 1547-51.

18- Zhang R, Wang H, Tian YY, Yu X, Hu T, Dummer PM. Use of cone-beam computed tomography to evaluate root and canal morphology of mandibular molars in Chinese individuals. International Endod. J. 2011; 44, 990-9.

19- Hess W. Anatomy of the root canals of the teeth of the permanent dentition: Part 1. New York City: William Wood; 1925 .

20- Mueller AH. Anatomy of root canals. JADA 1933; 20(8):1361- 86.

21- Bellizzi R, Hartwell G. Radiographic evaluation of root canal anatomy of in vivo endodontically treated maxillary premolars. J Endod 1985; 11(1):37-9.

22- Thomas RP, Moule AJ, Bryant R. Root canal morphology of maxillary permanent first molar teeth at various ages. Int Endod J 1993; 26(5):257-67.
23- Neelakantan P, Subbarao C, Ahuja R, Subbarao CV, Gutmann JL. Cone-beam computed tomography study of root and canal morphology of maxillary first and second molars in an Indian population. J Endod. 2010; 36(10):1622-7.

24- Wang Y, Zheng QH, Zhou XD et al. (2010) Evaluation of the root and canal morphology of mandibular first permanent molars in a western Chinese population by cone-beam computed tomography. J Endod 2010; 36, 1786-9.

25- Rhodes JS, Ford TR, Lynch JA, Liepins PJ, Curtis RV. Microcomputed tomography: a new tool for experimental endodontology. Int Endod J 1999; 32(3):165-70.

26- Baratto Filho F, Zaitter S, Haragushiku GA, de Campos EA, Abuabara A, Correr GM. Analysis of the internal anatomy of maxillary first molars by using different methods. J Endod 2009; 35:337-342.

27- Eder A, Kantor M, Nell A. Root canal system in the mesiobuccal root of the maxillary first molar: an in vitro comparison study of computed tomography and histology. Dento Maxillo Facial Radiol 2006; 35, 175-7.

28- Matherne RP, Angelopoulos C, Kulild JC, Tira D. Use of cone-beam computed tomography to identify root canal systems in vitro. J Endod 2008; 34, 87-9.

29- Patel S, Dawood A, Whaites E, Pitt Ford T. New dimensions in endodontic imaging: part 1. Conventional and alternative radiographic systems. Int Endod J 2009; 42(6):447-62.

30- Patel S. New dimensions in endodontic imaging: Part 2. Cone beam computed tomography. Int Endod J 2009; 42(6):463-75.

31- Danforth RA, Dus I, Mah J. 3-D volume imaging for dentistry: a new dimension. J Calif Dent Assoc. 2003; 31(11):817-23.

32- Lee KW, Kim Y, Perinpanayagam H. Comparison of alternative image reformatting techniques in micro-computed tomography and tooth clearing for detailed canal morphology. J Endod 2014; 40, 417-22.

33- Maret D, Peters OA, Galibourg A. Comparison of the accuracy of 3-dimensional cone-beam computed tomography and micro-computed tomography reconstructions by using different voxel sizes. J Endod 2014; 40,1321-6.

34- Kim Y, Perinpanayagam H, Lee JK. Comparison of mandibular first molar mesial root canal morphology using micro-computed tomography and clearing technique. Acta Odont Scand 2015; 73, 427-32. 
35- Rwenyonyi CM, Kutesa AM, Muwazi LM, Buwembo W. Root and canal morphology of maxillary first and second permanent molar teeth in a Ugandan population. Int Endod J. 2007; 40:679-83.

36- Al Shalabi RM, Omer OE, Glennon J, Jennings M, Claffey NM. Root canal anatomy of maxillary first and second permanent molars. Int Endod J. 2000; 33:405-14.

37- Sert S, Sahinkesen G, Topçu FT, Eroglu SE, Oktay EA. Root canal configurations of third molar teeth. A comparison with first and second molars in the Turkish population. Aust Endod J. 2011;37:109-17.

38- Wasti F, Shearer AC, Wilson NH. Root canal systems of the mandibular and maxillary first permanent molar teeth of south Asian Pakistanis. Int Endod J. 2001; 34:263-6.

39- Alavi AM, Opasanon A, Ng YL, Gulabivala K. Root and canal morphology of Thai maxillary molars. Int Endod J. 2002; 35:478-85.

40- Sert S, Bayirli GS. Evaluation of the root canal configurations of the mandibular and maxillary permanent teeth by gender in the Turkish population. J Endod. 2004;30:391-8.

41- Stephen C, Kenneth M. Cohen's Pathways of the Pulp Expert Consult. 10th ed; 2012; 31.

42- Vertucci FJ. Root canal morphology and its relationship to endodontic procedures. Endod Topics. 2005; 10:3-29.

43- De Pablo OV, Estevez R, Peix Sanchez M, Heilborn C, Cohenca N. Root anatomy and canal configuration of the permanent mandibular first molar: a systematic review. J Endod 2010; 36, 1919-31.

44- Reuben J, Velmurugan N, Kandaswamy D. The evaluation of root canal morphology of the mandibular first molar in an Indian population using spiral computed tomography scan: An in vitro study. J Endod. 2008; 34:121-249.

45- Alrahabi M and Zafar M.S. Evaluation of root canal morphology of maxillary molars using cone beam computed tomography Pak J Med Sci. 2015 Mar-Apr; 31(2): 426-430.

46- Sempira H, Hartwell G. Frequency of second mesiobuccal canals in maxillary molars as determined by use of an operating microscope: A clinical study. J Endod. 2000; 26(11):673-674.

47- Imura N, Hata GI, Toda T, Otani SM, Fagundes MI. Two canals in mesiobuccal root of maxillary molars. Int Endod J 1998; 31(6): 410-414.

48- Marroquin BB, El-Sayed MA, Willershausen-Zonnchen Morphology of the physiological foramen:I.Maxillary and mandibular molars. J Endod 2004; 30, 321-8.

49- Ibarrola JL, Knowles KI, Ludlow MO, Mcffinley Jr IB. Factors affecting the negotiability of second mesiobuccal canals in maxillary molars. J Endod 1997; 23(4): 236-238.

50- Habib A. Anatomical study of the mesiobuccal root in maxillary first molars. Journal of Taibah Uni Med Sci June 2014; Volume 9, Issue 2 :Pages 123-125.

51- Grande NM, Plotino G, Pecci R, Bedini R, PameijerCH, Somma F. Micro-computerized tomographic analysis of radicular and canal morphology of premolars with long oval canals. Oral Surg, Oral Med, Oral Pathol, Oral Radiol \& Endod 2008; 106, e70-6.

52- Tam A, Yu DC. Location of canal isthmus and accessory canals in the mesiobuccal root of maxillary first permanent molars. J Canad Dent Assoc. 2002; 68, 28-33.

53- Teixeira FB, Sano CL, Gomes BP, Zaia AA, Ferraz CC, SouzaFilho FJ. A preliminary in vitro study of the incidence and position of the root canal isthmus in maxillary and mandibular first molars. Int Endod J 2003; 36, 276-80.

54- Zhang R, Yang H, Yu X, Wang H, Hu T, Dummer PM. Use of CBCT to identify the morphology of maxillary permanent molar teeth in a Chinese subpopulation. Int Endod J. 2011; 44(2):162-9.37.

55- Rathi S, Patil J, Jaju PP. Detection of Mesiobuccal Canal in Maxillary Molars and Distolingual Canal in Mandibular Molars by Dental CT: A Retrospective Study of 100 Cases. Int Dent J. 2010; 2010:291276.

56- Zheng QH, Wang Y, Zhou XD, Wang Q, Zheng GN, Huang DM. A cone-beam computed tomography study of maxillary first permanent molar root and canal morphology in a Chinese population. J Endod. 2010; 36(9):1480-4.38. 